\section{Commentary: The complexity of complications}

\author{
Marvin D. Atkins, MD, and Michael J. Reardon, MD
}

In this edition of the Journal, the structural heart team from the Brigham and Women's Hospital in Boston present their midterm outcomes of transfemoral transcatheter aortic valve replacement in 866 patients. ${ }^{1}$ The mean patient age was 80 years, and $>60 \%$ were deemed intermediate or high risk. The majority of patients received a balloon- expandable device $(86.5 \%)$ and were treated with the latest generation of balloon- expandable or selfexpanding prostheses $(71 \%)$. The study focused on periprocedural complications and their longitudinal outcomes on mid-term survival. The group reported low mortality at 30 days $(2.8 \%)$ and a 1 -year mortality of $11.8 \%$, even in these intermediate- and high-risk groups. A new permanent pacemaker (PPM) was required in $7.9 \%$ of patients, and this did not appear to have an effect on survival at 5 years. Greater than mild paravalvular leak (PVL) occurred in $4.4 \%$, and survival at 2 years was significantly worse in these patients compared with those with mild PVL. This mortality risk appeared to be attenuated at 5 years for unclear reasons. Any new postoperative stroke occurred in $3.9 \%$ and was categorized as mild, moderate, and severe. Severe stroke occurred in 7 patients $(0.8 \%)$ and was associated with significantly worse 5-year survival. Nonsevere stroke was not associated with an increased mortality risk. The groups of patients were divided into an early era (2011-2014) and a late era (2015-2018), and the previous outcomes were examined. Over the time intervals, PVL greater than mild decreased significantly as operator experience, patient selection, and

From the Department of Cardiovascular Surgery, Houston Methodist Hospital, Houston, Tex.

Disclosures: The authors reported no conflicts of interest.

The Journal policy requires editors and reviewers to disclose conflicts of interest and to decline handling or reviewing manuscripts for which they may have a conflict of interest. The editors and reviewers of this article have no conflicts of interest.

Received for publication April 25, 2021; revisions received April 25, 2021; accepted for publication April 26, 2021; available ahead of print May 4, 2021.

Address for reprints: Michael J. Reardon, MD, Department of Cardiothoracic Surgery, Houston Methodist Hospital, 6550 Fannin, Suite 1401, Houston, TX 77030 (E-mail: mreardon@houstonmethodist.org).

J Thorac Cardiovasc Surg 2023;165:1356-7

$0022-5223 / \$ 36.00$

Copyright (c) 2021 by The American Association for Thoracic Surgery

https://doi.org/10.1016/j.jtcvs.2021.04.080

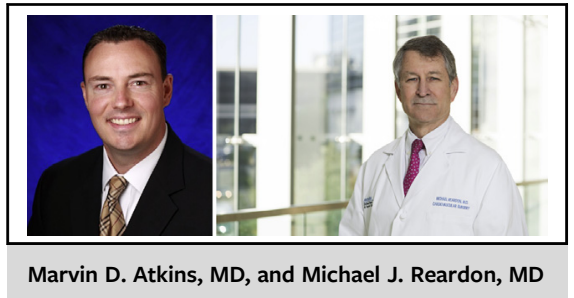

CENTRAL MESSAGE

The complications of stroke, paravalvular leak and pacemaker can affect the long term outcome from transfemoral TAVR. Low risk TAVR should focus on reducing these.

changes in transcatheter aortic valve replacement (TAVR) device design improved.

The authors should be commended for their excellent results. They highlight the (fortunately) infrequent complications associated with TAVR, namely new stroke, greater than mild PVL, and the need for a new PPM. Efforts to further improve the results of TAVR should be focused on mitigating the risks of these 3 specific complications. The outcomes of this study cannot be extrapolated to low-risk patients, given that the majority of patients were in the intermediate- and high-risk cohorts. Presumably, low-risk patients should have a lower atherosclerotic aortic arch burden and thus a lower risk of periprocedural stroke, as was seen in the low-risk trials, leading to a lowrisk indication. ${ }^{2,3}$ Low-risk patients are also are less likely to have preexisting conduction disturbances, increasing their likelihood of needing a new PPM. Rates greater than mild PVL continue to be low, especially with improvements in device design, but might be adversely affected in those low-risk patients who are more likely to present with bicuspid disease and eccentric calcium deposits.

TAVR has been shown in randomized clinical trials to have equivalent ${ }^{4-6}$ or superior $^{7}$ outcomes in patients with intermediate or high surgical risk, and the TAVR results in the present study are in line with those findings. Continuing advances in device design, deployment techniques, and stroke prevention are aimed at mitigating 3 of the most common, albeit low-risk, complications of TAVR: new PPM, greater than mild PVL, and periprocedural stroke. As TAVR is increasingly performed in 
patients at low surgical risk, of younger age, and with longer life expectancy, the longitudinal outcomes of these adverse events will play a significant role. The low-risk trials for TAVR plan to follow patients out to 10 years, and the midterm results should be available in the next 2 to 3 years to shed further light of the results of TAVR and surgical AVR (SAVR) in this low-risk patient population. As long as TAVR has at least equivalent intermediate-term results to SAVR, patients will continue to demand this less invasive option.

\section{References}

1. Percy ED, Harloff M, Hirji S, Tartarini RJ, McGurk S, Cherkasky O, et al. Outcomes of procedural complications in transfemoral transcatheter aortic valve replacement. J Thorac Cardiovasc Surg. 2023;165:1346-55.e5.
2. Mack MJ, Leon MB, Thourani VH, Makkar R, Kodali SK, Russo M, et al. Transcatheter aortic-valve replacement with a balloon-expandable valve in low-risk patients. N Engl J Med. 2019;380:1695-705.

3. Popma JJ, Deeb GM, Yakubov SJ, Mumtaz M, Gada H, O’Hair D, et al. Transcatheter aortic-valve replacement with a self-expanding valve in low-risk patients. $N$ Engl J Med. 2019:380:1706-15.

4. Leon MB, Smith CR, Mack MJ, Makkar RR, Svensson LG, Kodali SK, et al Transcatheter or surgical aortic-valve replacement in intermediate-risk patients. N Engl J Med. 2016;374:1609-20.

5. Smith CR, Leon MB, Mack MJ, Miller DC, Moses JW, Svensson LG, et al. Transcatheter versus surgical aortic-valve replacement in high-risk patients. $N$ Engl J Med. 2011;364:2187-98.

6. Reardon MJ, Van Mieghem NM, Popma JJ, Kleiman NS, Søndergaard L, Mumtaz M, et al. Surgical or transcatheter aortic-valve replacement in intermediate-risk patients. N Engl J Med. 2017;376:1321-31.

7. Adams DH, Popma JJ, Reardon MJ, Yakubov SJ, Coselli JS, Deeb GM, et al Transcatheter aortic-valve replacement with a self-expanding prosthesis. $N$ Engl J Med. 2014;370:1790-8.
See Article page 1346.

\section{Commentary: Mid-term outcomes in a real-world transcatheter aortic valve replacement population}

\author{
Rachel Eikelboom, MD, \\ Aaron J. Spooner, MD, MEHP, MMgt, and \\ Michael H. Yamashita, MDCM, MPH
}

In this edition of the Journal, Percy and colleagues ${ }^{1}$ present a series of 866 patients who underwent transfemoral transcatheter aortic valve replacement (TAVR) at Brigham and Women's Hospital between 2011 and 2018. The authors compared 5-year survival in patients with and without periprocedural complications. The complications of interest were periprocedural stroke, paravalvular leak (PVL), new

\footnotetext{
From the Department of Surgery, Max Rady College of Medicine, University of Manitoba; and Cardiac Sciences Program, St Boniface Hospital, Winnipeg, Manitoba, Canada.

Disclosures: The authors reported no conflicts of interest.

The Journal policy requires editors and reviewers to disclose conflicts of interest and to decline handling or reviewing manuscripts for which they may have a conflict of interest. The editors and reviewers of this article have no conflicts of interest.

Received for publication May 10, 2021; revisions received May 10, 2021; accepted for publication May 11, 2021; available ahead of print May 14, 2021.

Address for reprints: Michael H. Yamashita, MDCM, MPH, Department of Surgery, Max Rady College of Medicine, University of Manitoba, Y3519 - 409 Tache Ave,

Winnipeg, Manitoba, Canada R2H 2A6 (E-mail: myamashita@sbgh.mb.ca).

J Thorac Cardiovasc Surg 2023;165:1357-8

$0022-5223 / \$ 36.00$

Copyright (c) 2021 by The American Association for Thoracic Surgery

https://doi.org/10.1016/j.jtcvs.2021.05.017
}

Check for updates

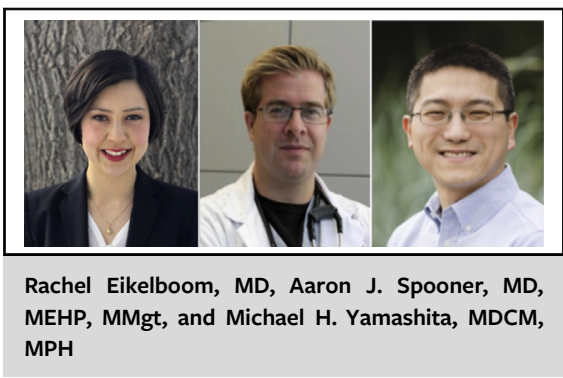

CENTRAL MESSAGE

Midterm survival after TAVR is lower in high- and intermediaterisk patients who have a severe perioperative stroke. The impact of complications on outcomes in low-risk patients requires more

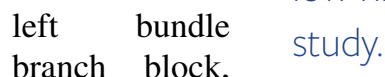
and permanent pacemaker

(PPM) implantation. These complications appear to occur more frequently after TAVR than surgical aortic valve replacement (SAVR) in some randomized trials. ${ }^{2-4}$ Their impact on long-term prognosis is of particular concern in younger, low-risk patients who would also be excellent candidates for SAVR, which has proven excellent long-term outcomes. $^{5}$

Patients in this study had a mean age of 80 years, a mean Society of Thoracic Surgery surgical risk score of $4.8 \%$, and were followed for a median of 36 months. Stroke 